We have found that the concentration of citric acid in the isthmus is not altered in birds injected with fluoroacetate, and the enzymes of the Krebs cycle which seem most likely to be implicated in the high citric acid content of this region are under investigation.

The tubular region of the uterus adjacent to the isthmus, the isthmo-uterine junction ${ }^{6}$, is considerably richer in calcium and citric acid than the thick muscular region where the main process of shell calcification occurs, and this may be due to the fact that the transition from isthmus to uterus is gradual, there being no definite histological boundary between the two regions?.

Magnesium forms a complex ion with citrate $^{8}$ similar to that formed between calcium and citrate; but in spite of the large variations in citric acid in the different segments, the magnesium content of the isthmus and uterus is constant at a level of 15-20 mgm./100 gm. The magnum, however, which is relatively low in citric acid (less than $10 \mathrm{mgm} . / 100$ gm.) contains approximately twice as much magnesium (38 mgm./100 gm.) as any other region of the oviduct.

We wish to thank Dr. B. C. Saunders for a generous gift of sodium fluoroacetate.

T. G. TAYLOR

F. Hertelendy

Department of Physiological Chemistry,

The University,

Reading. 1 Taylor, T. G., 'Moore, J. H., and Hertelendy, F., Brit. J. Nutr., 14,

2 Taylor, T. G., Biochem. J., 54, 48 (1953).

'Buffa, P., and Peters, R. A., J. Physiol., 110, 488 (1949).

'Lapidus, M., and Mellon, E. F., J. Assoc. Off. Agric. Chem., 41, 411 (1958).

"Schwarzenbach, G., "Complexometric Titrations" (Methuen and Co., Ltd., London, 1957).

- Richardson, K. C., Phil. Trans. Roy. Soc., B, 225, 149 (1935),

'Bradley, O. C., J. Anat., 62, 339 (1927-28).

'Hastings, A. B., McLean, F. C., Eichelberger, L., Hall, J. L., and Da Costa, E., J. Biol. Chem., 107, 351 (1934).

\section{Oxytocin in the Neurohypophysis of the Laying Hen}

Axthough it has been well known that the administration of posterior lobe hormones induces premature oviposition in the hen, Gallus domesticus ${ }^{1,2}$, as in other fowls ${ }^{3}$, it remains undetermined whether the hormone(s) plays an essential part in normal oviposition. The results presented here may throw light on the mechanism of oviposition in the domestic fowl.

Twenty-five White Leghorn hens in their first year of production were killed at the following times: (1) 3-4 hr. before expected oviposition; (2) within an hour before expected oviposition; (3) within 5 min. after oviposition ; (4) 1-2 hr. after oviposition; (5) 5-6 hr. after oviposition. The posterior lobes of the hypophysis of each bird were extracted with 0.25 per cent acetic acid immediately after removal, and assayed for oxytocic activity against 'Pitocin' (Parke, Davis and Co.) on the isolated uterus of an œstrous virgin rat of Wistar strain, following Holton's method ${ }^{4}$. Dibenamine and atropine were added to the organ-bath.

Fig. 1 shows the mean hormone content per lobe and its 25 per cent fiducial limits. The differences between the lobes removed within $5 \mathrm{~min}$. after oviposition and those removed at other times were

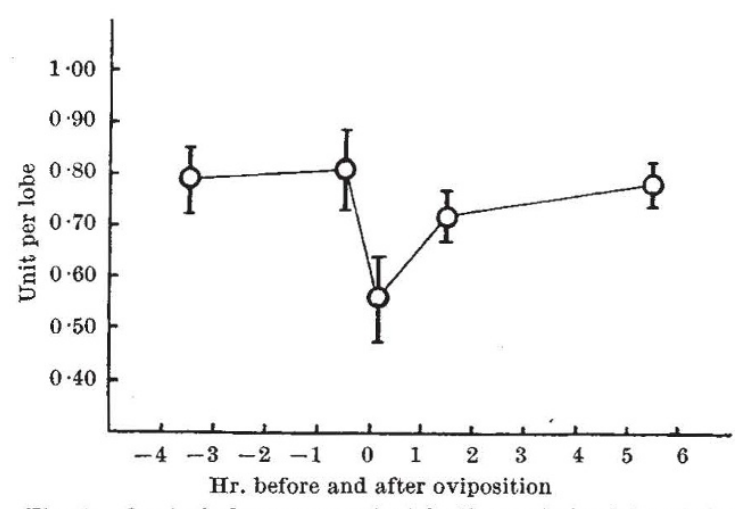

Fig. 1. Oxytocic hormone content in the posterior lobe of the hypophysis before and after oviposition. Each circle represents lines represent the flducial limits of the mean (degree of confidence, 0.95 )

significant $(P<0.01)$. These differences were not materially affected by using other criteria of comparison ; for example, hormone content per milligram neurohypophysial tissue. No significant difference was found between the weights of the posterior lobes.

It would appear then that oviposition in the hen follows depletion of oxytocic hormone from the posterior lobe, and that the hormone accumulates in the hypophysis soon after oviposition.

Laboratory of Animal Breeding,

KatuHide TANaKa Serrchi Nakajo

Faculty of Agriculture,

Nagoya University, Japan. Feb. 2.

${ }^{1}$ Burrows, W. H., and Byerly, T. C., Poultry Sci., 21, 416 (1942). ${ }^{2}$ Burrows, W. H., and Fraps, R. M., Endocrinol., 30, 702 (1942). ${ }^{3}$ Riddle, O., Science, 54, 664 (1921).

${ }^{4}$ Holton, P., Brit. J. Pharmacol., 3, 328 (1948).

\section{Hunger Reduction produced by Injecting Glucose into the Lateral Ventricle of the Rat}

IT has been repeatedly shown that the ventromedial nucleus of the hypothalamus is responsible for the satiation of hunger. According to Mayer ${ }^{1}$, this is brought about by hypothalamic glucoreceptors. Because of the rapid removal of injected glucose from the blood-stream, direct experimental tests of Mayer's hypothesis have yielded conflicting results.

The technique of intraventricular injection em. ployed in the present experiment is a modification of that developed by Feldberg and Sherwood ${ }^{2}$ for use on cats, and details will be published elsewhere. In brief, a stainless steel cannula is stereotaxically implanted and permanently fixed in the lateral ventricle, and the animal is allowed to recover from the anæsthetic. Correct positioning is checked by injecting the satiated rat with a small quantity of 2 per cent saline through the cannula. If the cannula tip is in the ventricular system, the injected fluid reaches the hypothalamic osmoreceptors and the animal responds by drinking water. The validity of this test has been confirmed at autopsy by injecting a dye through the cannula.

The unrestrained animals are injected with an electrically driven micrometer syringe connected to the cannula by polythene tubing at a rate of 0.005 $\mathrm{ml} . / \mathrm{min}$., to a total volume of $0.2 \mathrm{ml}$. $/ \mathrm{kgm}$. body. weight. Such injections per se do not appear to 